\title{
Extraction Behavior and Separation of Lanthanides with a Diglycol Amic Acid Derivative and a Nitrogen-donor Ligand
}

\author{
Kojiro Shimojo, ${ }^{* \dagger}$ Hirochika Naganawa,* Junji Noro, ${ }^{* *}$ Fukiko Kubota,*** \\ and Masahiro GoTo $* * *$ \\ *Division of Environment and Radiation Sciences, Nuclear Science and Engineering Directorate, \\ Japan Atomic Energy Agency, Tokai, Ibaraki 319-1195, Japan \\ **Research Department, NISSAN ARC, LTD., Yokosuka 237-0061, Japan \\ ***Department of Applied Chemistry, Graduate School of Engineering and Center for Future Chemistry, \\ Kyushu University, 744 Motooka, Fukuoka 819-0395, Japan
}

\begin{abstract}
The extraction and separation of lanthanides have been investigated using CHON-type extractants, which are composed of only $\mathrm{C}, \mathrm{H}, \mathrm{O}$, and $\mathrm{N}$ atoms. $\mathrm{N}, \mathrm{N}$-Dioctyldiglycol amic acid (DODGAA) showed high extraction and separation performances for heavier lanthanides compared with typical CHON-type extractants. On the other hand, $N, N, N^{\prime}, N^{\prime}-$ tetrakis(2-pyridylmethyl)ethylenediamine (TPEN) provided an unprecedentedly high selectivity for lighter lanthanides. Furthermore, it was found that the combination of DODGAA and TPEN under suitable conditions enabled the mutual separation of light, middle, and heavy lanthanides.
\end{abstract}

(Received September 3, 2007; Accepted October 24, 2007; Published December 10, 2007)

\section{Introduction}

Lanthanides are very important metals in high-technology industry because of their unique electronic, optical, and magnetic properties, and therefore their demand has been increasing in recent years. Lanthanides have very similar fundamental chemical properties, which makes it difficult to separate them into individual elements. That is a major reason why lanthanides are expensive.

Liquid-liquid extraction is one of the most effective analytical methods for the separation and purification of various metal ions. The extractant plays a key role in the extraction efficiency and the separation operation. The selection of an appropriate extractant often determines the success of an extraction process. In the extraction separation of lanthanides, commercial organophosphorus extractants, such as D2EHPA and PC-88A, are typically employed. ${ }^{1-3}$ The organophosphorus extractants show high extraction and separation performances for lanthanides. However, the extractants are not fully combustible, leaving phosphorous residues as secondary wastes. Thus, extractants composed of only $\mathrm{C}, \mathrm{H}, \mathrm{O}$, and $\mathrm{N}$ atoms (the $\mathrm{CHON}$ principle) have attracted much attention as a green extractant to establish a new residual waste-free extraction process based on their complete combustibility. To date, a variety of CHON-type extractants have been developed for the extraction of lanthanides, for example, carboxylic acid type compounds, ${ }^{4} \beta$ diketones, ${ }^{5}$ and calixarenes. ${ }^{6}$ However, almost all CHON-type extractants provide low extraction and separation performances for lanthanides compared with organophosphorus extractants.

In the present study, we focused attention on two CHON-type

$\dagger$ To whom correspondence should be addressed.

E-mail: shimojo.kojiro@jaea.go.jp extractants for mutual separation among lanthanide elements. One was $N, N$-dioctyldiglycol amic acid (DODGAA, Fig. 1), which is an anionic tridentate ligand with a carbamoyl group and a carboxy group connected by an ether chain. The other was $N, N, N^{\prime}, N^{\prime}$-tetrakis(2-pyridylmethyl)ethylenediamine (TPEN, Fig. 1), ${ }^{8-11}$ which is a neutral hexadentate ligand with four pyridyl groups connected by ethylenediamine. Diglycolamide and nitrogen-donor type extractants have been under intense study concerning extraction and group separation of actinides and lanthanides in the field of nuclear industry, ${ }^{12,13}$ and also offer considerable potential as extractants for mutual separation among lanthanide elements. We describe herein that DODGAA and TPEN have rather simple $\mathrm{CHON}$-structures but provide unprecedentedly high separation performances for the individual lanthanide elements.

\section{Experimental}

\section{Reagents and materials}

The extractant TPEN was purchased from Dojindo (Kumamoto, Japan). Dioctylamine was purchased from Aldrich

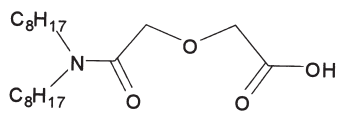

DODGAA

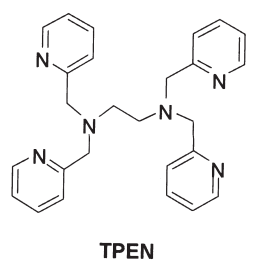

TPEN
Fig. 1 Molecular structures and abbreviations of extractants. 
Chemical Co., Inc. (Milwaukee, WI). Diglycolic anhydride was obtained from Tokyo Kasei Kogyo Co., Inc. (Tokyo, Japan). Lanthanide(III) nitrates (all lanthanides, except for Pm(III), which is a radioactive element) were purchased from Kishida Chemical Co. Ltd. (Osaka, Japan). All other regents were of commercially available analytical grade and used as received.

\section{Synthesis of DODGAA}

The extractant DODGAA was synthesized as described previously. ${ }^{7}$ Briefly, the synthetic procedure was as follows: to a slurry of diglycolic anhydride $(4.17 \mathrm{~g}, 35.9 \mathrm{mmol})$ in $\mathrm{CH}_{2} \mathrm{Cl}_{2}$ (40 mL), dioctylamine (7.0 g, $28.4 \mathrm{mmol})$ dissolved in $\mathrm{CH}_{2} \mathrm{Cl}_{2}$ $(10 \mathrm{~mL})$ was carefully added; the mixture was stirred at room temperature overnight. The resulting clear solution was washed with deionized water 4 times. After the organic layer was dried with anhydrous sodium sulfate, the solvent was removed in vacuo, and the residue was recrystallized from hexane; white powder $9.57 \mathrm{~g}$ (94.2\% yield); ${ }^{1} \mathrm{H} \mathrm{NMR}\left(400 \mathrm{MHz}, \mathrm{CDCl}_{3}, \mathrm{TMS}\right.$, $\left.25^{\circ} \mathrm{C}\right) \delta 0.89\left(\mathrm{t}, 6 \mathrm{H}, \mathrm{N}-\left(\mathrm{CH}_{2}\right)_{7}-\mathrm{CH}_{3}\right), 1.29,1.55\left(\mathrm{~s}, 24 \mathrm{H}, \mathrm{N}-\mathrm{CH}_{2-}\right.$ $\left.\left(\mathrm{CH}_{2}\right)_{6}-\mathrm{CH}_{3}\right), 3.10,3.35$ (t, $\left.4 \mathrm{H}, \mathrm{N}-\mathrm{CH}_{2}-\mathrm{C}_{7} \mathrm{H}_{15}\right), 4.22(\mathrm{~s}, 2 \mathrm{H}, \mathrm{N}-$ $\left.\mathrm{CO}-\mathrm{CH}_{2}-\mathrm{O}\right), 4.40$ (s, 2H, $\left.\mathrm{CH}_{2}-\mathrm{COOH}\right)$; Anal. Calcd for $\mathrm{C}_{20} \mathrm{H}_{39} \mathrm{O}_{4} \mathrm{~N}_{1}$ : C, 67.19; H, 10.99; N, 3.92. Found: C, 66.99; H, $11.00 ; \mathrm{N}, 3.94$.

\section{Extraction procedure}

Organic phases were prepared by dissolving $10 \mathrm{mM}(1 \mathrm{M}=1$ $\left.\mathrm{mol} / \mathrm{dm}^{3}\right)$ DODGAA in isooctane containing $5 \mathrm{vol} \%$ 1-octanol as a solubilizer or $5 \mathrm{mM}$ TPEN in nitrobenzene. Aqueous phases were prepared by dissolving $0.01 \mathrm{mM} \mathrm{Ln}\left(\mathrm{NO}_{3}\right)_{3}$ (all lanthanides, except for $\mathrm{Pm}(\mathrm{III})$ ). In an experiment with DODGAA, $\mathrm{HNO}_{3}$ was used to adjust the $\mathrm{pH}$ from 0.5 to 5 . In the case of TPEN, the ionic strength was adjusted from 0 to $1 \mathrm{M}$ by $\mathrm{NH}_{4} \mathrm{NO}_{3}$ at $\mathrm{pH}$ 5. Equal volumes of the organic and aqueous solutions were mixed and shaken on a vortex mixer at $298 \mathrm{~K}$ for $15 \mathrm{~min}$ to attain equilibrium. These mixtures were then centrifuged for 3 min to promote phase separation. After each phase was separated, the metal ions in the organic phase were backextracted into $1 \mathrm{M} \mathrm{HNO}_{3}$ in the DODGAA system or $0.1 \mathrm{M}$ $\mathrm{HNO}_{3}$ in the TPEN system. The concentrations of $\mathrm{Ln}^{3+}$ in the aqueous phase and the organic phase were determined by using inductively coupled plasma mass spectrometry (ICP-MS, Hewlett Packard HP 4500) to obtain the extractability $\left(E=\left[\operatorname{Ln}^{3+}\right]_{\text {org }} /\left[\operatorname{Ln}^{3+}\right]_{\text {ini }} \times 100\right)$, the distribution ratio $(D=$ $\left.\left[\mathrm{Ln}^{3+}\right]_{\text {org }} /\left[\mathrm{Ln}^{3+}\right]_{\mathrm{aq}}\right)$, and the separation factor $\left(S F_{\mathrm{Ln} / \mathrm{Ln}^{\prime}}=D_{\mathrm{Ln}} / D_{\mathrm{Ln}^{\prime}}\right)$. The subscript org., aq, and ini denote the organic phase, the aqueous phase, and the initial condition, respectively. The equilibrium $\mathrm{pH}$ values in the aqueous phase were also measured.

\section{Results and Discussion}

Figure 2 shows the extraction behavior of 14 lanthanide(III) ions (all lanthanides, except for Pm(III)) from the aqueous phase into the organic phase using DODGAA as a function of the equilibrium $\mathrm{pH}$ in the aqueous phase. The transfer of lanthanide ions using DODGAA is promoted with increasing $\mathrm{pH}$. Finally, quantitative extraction is achieved in moderately-acidic solutions $(1 \leq \mathrm{pH} \leq 3)$. On the other hand, it is known that typical carboxylic acid-type extractants, such as Versatic 10 , extract lanthanides under neutral conditions $(6 \leq \mathrm{pH} \leq 7) .{ }^{14}$ The result shows that DODGAA provides an exceptionally high extraction performance for lanthanides compared with typical CHON-type extractants. In fact, the extraction performance of DODGAA is comparable to that of organophosphorus extractants (e.g. D2EHPA and PC-88A). ${ }^{7}$ It was confirmed that the $\mathrm{pH}$

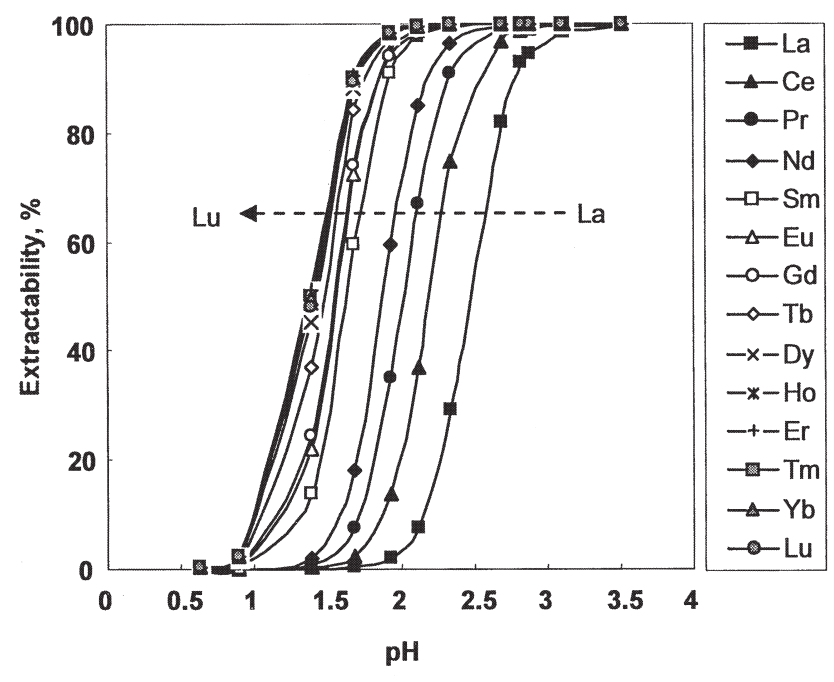

Fig. 2 Extractability of 14 lanthanides using DODGAA as a function of the $\mathrm{pH}$. [DODGAA] $=10 \mathrm{mM} ;\left[\mathrm{Ln}^{3+}\right]=0.01 \mathrm{mM}$.

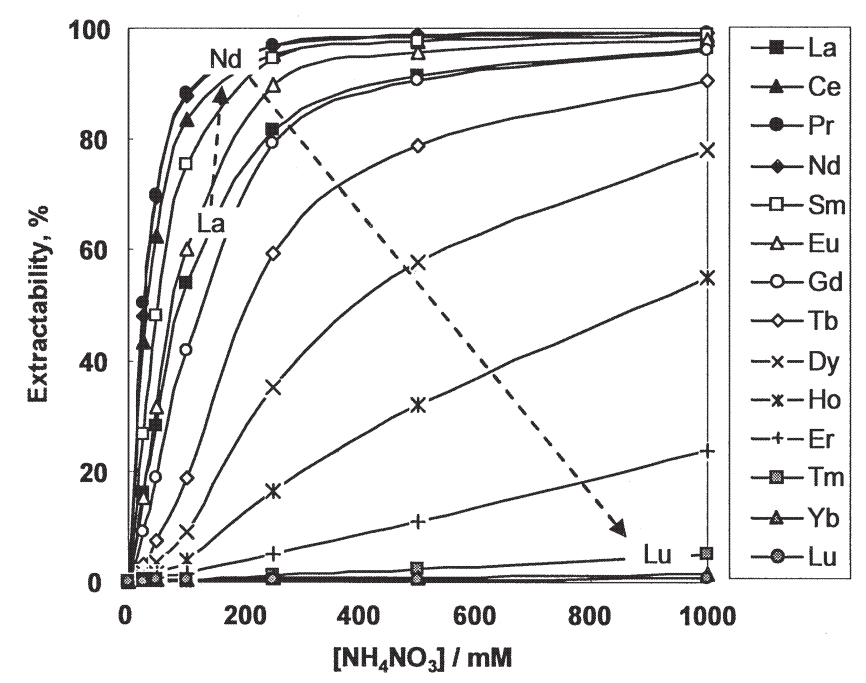

Fig. 3 Extractability of 14 lanthanides using TPEN with increasing $\mathrm{NH}_{4} \mathrm{NO}_{3}$ concentration. [TPEN] $=5 \mathrm{mM} ;\left[\mathrm{Ln}^{3+}\right]=0.01 \mathrm{mM} ; \mathrm{pH}_{\text {ini }}, 5$.

value is reduced after extraction, because the transfer of lanthanides using DODGAA proceeds through a protonexchange mechanism. By analyzing these extraction data, a slope analysis was conducted as a function of the equilibrium $\mathrm{pH}$ in the aqueous phase (data not shown). Linear relationships between $\log D$ and the $\mathrm{pH}$ with a slope of 3 were obtained for all 14 lanthanides, suggesting that three protons from DODGAA molecules are released to form a neutral complex with trivalent lanthanides. Furthermore, it was found that DODGAA exhibits high selectivity for heavier lanthanides from $\mathrm{Tb}^{3+}$ to $\mathrm{Lu}^{3+}$, which is very similar to the selectivity of D2EHPA. ${ }^{7}$ The high extraction and separation performances of DODGAA are attributed to an electrostatic interaction, a cation-oxygen-donor interaction, and a chelate effect created by the tridentate diglycol amic acid frame.

Figure 3 shows the extraction behavior of 14 lanthanide(III) ions using TPEN as a function of the $\mathrm{NH}_{4} \mathrm{NO}_{3}$ concentration in the aqueous phase. The extractability of lanthanides is enhanced with increasing $\mathrm{NH}_{4} \mathrm{NO}_{3}$ concentration, indicating that $\mathrm{NO}_{3}{ }^{-}$is indispensable for metal extraction using TPEN to form an ion 
Table 1 Extraction separation of light, middle, and heavy lanthanide ions with a combination of TPEN and DODGAA

\begin{tabular}{|c|c|c|c|c|c|c|c|c|c|c|}
\hline & \multirow{2}{*}{$\begin{array}{c}{\left[\mathrm{Ln}^{3+}\right]_{\text {inin }} /} \\
\mu \mathrm{M}\end{array}$} & \multicolumn{3}{|c|}{ First stage, TPEN ${ }^{a}$} & \multirow{2}{*}{$\begin{array}{c}{\left[\operatorname{Ln}^{3+}\right]^{\prime}{ }_{\text {ini }}^{\mathrm{d}} /} \\
\mu \mathrm{M}\end{array}$} & \multicolumn{3}{|c|}{ Second stage, DODGAA ${ }^{c}$} & \multirow{2}{*}{$\begin{array}{c}\text { Recovery } \\
\%\end{array}$} & \multirow{2}{*}{$\begin{array}{c}\text { Purityg, } \\
\quad \%\end{array}$} \\
\hline & & {$\left[\mathrm{Ln}^{3+}\right]_{\mathrm{aq}} / \mu \mathrm{M}$} & {$\left[\mathrm{Ln}^{3+}\right]_{\mathrm{back}} \mathrm{b} / \mu \mathrm{M}$} & $E, \%$ & & {$\left[\mathrm{Ln}^{3+}\right]_{\mathrm{aq}} / \mu \mathrm{M}$} & {$\left[\operatorname{Ln}^{3+}\right]_{\text {back }} \mathrm{e} / \mu \mathrm{M}$} & $E, \%$ & & \\
\hline $\mathrm{La}^{3+}$ & 9.65 & 0.39 & 9.25 & 96 & 9.25 & 8.87 & 0.39 & 4 & 92 & 98 \\
\hline $\mathrm{Eu}^{3+}$ & 9.21 & 0.23 & 8.98 & 98 & 8.98 & 0.20 & 8.64 & 97 & 94 & 92 \\
\hline $\mathrm{Lu}^{3+}$ & 10.06 & 9.65 & 0.41 & 4 & 0.41 & 0.00 & 0.40 & 99 & 96 & 94 \\
\hline
\end{tabular}

a. Organic phase: $\left[\right.$ TPEN] $=5 \mathrm{mM}$ in nitrobenzene; aqueous phase, $\mathrm{HNO}_{3}\left(\mathrm{pH}_{\text {ini }}, 5\right)$; $\left[\mathrm{NH}_{4} \mathrm{NO}_{3}\right]=1 \mathrm{M} . \mathrm{b}$. $\left[\mathrm{Ln}^{3+}\right]_{\text {back }}$ is the concentration of lanthanide ions in the receiving phase $\left(\mathrm{HNO}_{3} ; \mathrm{pH}_{\text {ini }}, 1.5\right)$ after back-extraction. The equilibrium $\mathrm{pH}$ in the receiving phase rose to 2.0 due to the protonation of TPEN. c. Organic phase: [DODGAA] $=10 \mathrm{mM}$ in isooctane $(5 \mathrm{vol} \%$ 1-octanol). d. The receiving phase in the TPEN system was employed as-is as the initial aqueous phase. e. Receiving phase: $1 \mathrm{M} \mathrm{HNO}_{3}$. f. Recovery, the concentration of recovered $\mathrm{Ln}^{3+}$ (bold value) $/\left[\mathrm{Ln}^{3+}\right]_{\mathrm{ini}} \times 100$. g. Purity, the concentration of recovered $\mathrm{Ln}^{3+}($ bold value $) /\left(\left[\mathrm{La}^{3+}\right]_{\mathrm{aq}}+\left[\mathrm{Eu}^{3+}\right]_{\mathrm{aq}}+\left[\mathrm{Lu}^{3+}\right]_{\mathrm{aq}}\right) \times 100$.

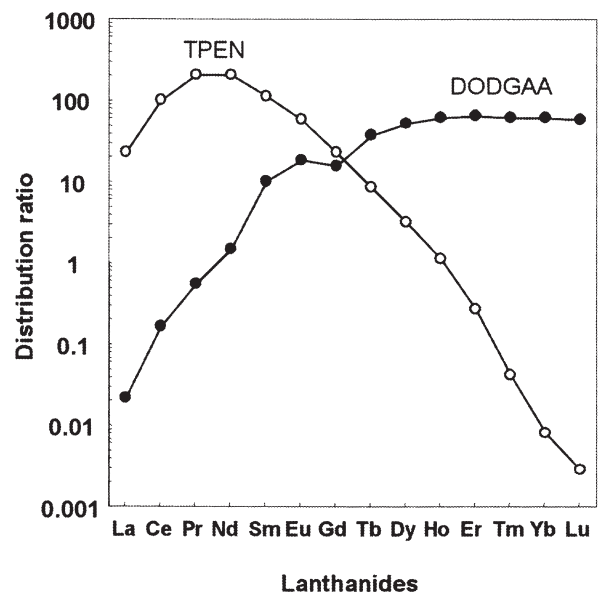

Fig. 4 Selectivity for 14 lanthanides using DODGAA or TPEN. $[$ DODGAA $]=10 \mathrm{mM} ;[$ TPEN $]=5 \mathrm{mM}$; aqueous phase, $0.01 \mathrm{mM}$ $\mathrm{Ln}^{3+}$ in $\mathrm{HNO}_{3}\left(\mathrm{pH}_{\text {ini }}, 2\right)$ when using DODGAA or $0.01 \mathrm{mM} \mathrm{Ln}^{3+}$ in 1 $\mathrm{M} \mathrm{NH}_{4} \mathrm{NO}_{3}\left(\mathrm{pH}_{\text {ini }}, 5\right)$ when using TPEN.

pair between the $\mathrm{Ln}^{3+}-\mathrm{TPEN}$ complex cation and $\mathrm{NO}_{3}{ }^{-}{ }^{-15}$ TPEN provides high extraction performance and selectivity for lighter lanthanides from $\mathrm{La}^{3+}$ to $\mathrm{Gd}^{3+}$, and offers little partitioning of heavier lanthanides from $\mathrm{Tm}^{3+}$ to $\mathrm{Lu}^{3+}$, even in a highconcentration $\mathrm{NH}_{4} \mathrm{NO}_{3}$ solution.

The distribution ratios of 14 lanthanide(III) ions using DODGAA or TPEN are shown in Fig. 4. In the DODGAA system, heavier lanthanide ions are effectively extracted. The separation factor between $\mathrm{La}^{3+}$ and $\mathrm{Lu}^{3+}\left(S F_{\mathrm{Lu} / \mathrm{La}}\right)$, which is defined by $D_{\mathrm{Lu}} / D_{\mathrm{La}}$, is approximately 2990 . This value is comparable to that in the organophosphorus extractants system $\left(S F_{\mathrm{Lu}} / \mathrm{La}=6800\right) .^{7}$ On the other hand, in the TPEN system, lighter lanthanide ion, especially $\mathrm{Pr}^{3+}$ and $\mathrm{Nd}^{3+}$, are selectively transferred. $S F_{\mathrm{Nd} / \mathrm{Lu}}$ between $\mathrm{Nd}^{3+}$ and $\mathrm{Lu}^{3+}$ is higher than 70000 , which is an unprecedentedly high value compared with that of previous studies on the mutual separation of lanthanide elements.

We performed a mutual separation experiment of light, middle, and heavy lanthanide ions with a combination of TPEN and DODGAA (Table 1). $\mathrm{La}^{3+}, \mathrm{Eu}^{3+}$ and $\mathrm{Lu}^{3+}$ were employed as representatives of light, middle, and heavy lanthanide ions, respectively. In the first stage using TPEN, $\mathrm{La}^{3+}$ and $\mathrm{Eu}^{3+}$ were quantitatively extracted into the organic phase, and $\mathrm{Lu}^{3+}$ remained in the aqueous phase. This result indicates that only $\mathrm{Lu}^{3+}$ was effectively separated from the other lanthanides. The stripping of lanthanide ions from the organic phase into a receiving phase was successfully achieved using a $\mathrm{HNO}_{3}$ solution ( $\mathrm{pH}$ 1.5). In the second stage using DODGAA, the receiving phase was employed as the initial aqueous phase without modification. Only $\mathrm{Eu}^{3+}$ was selectively transferred into the organic phase, which led to efficient separation between $\mathrm{La}^{3+}$ and $\mathrm{Eu}^{3+}$. Extracted $\mathrm{Eu}^{3+}$ was completely stripped using $1 \mathrm{M}$ $\mathrm{HNO}_{3}$. As a result, the recovery ratios of $\mathrm{La}^{3+}, \mathrm{Eu}^{3+}$, and $\mathrm{Lu}^{3+}$ were 92,94 , and $96 \%$, respectively. Furthermore, the purities were 98,92 , and $94 \%$, respectively.

\section{Conclusions}

We investigated the extraction behavior and the separation of lanthanides using DODGAA and TPEN as a CHON-type extractant. DODGAA is capable of the quantitative extraction of lanthanides in moderately-acidic solutions, and shows a high separation performance for heavier lanthanides. In the TPEN system, an exceptionally high selectivity for lighter lanthanides was achieved. Furthermore, we succeeded in the mutual separation of light, middle, and heavy lanthanides using DODGAA and TPEN. These findings highlight the great potential of a CHON-type ligand as a green extractant for lanthanide separation.

\section{Acknowledgements}

This research was financially supported by a Grant-in-Aid for Scientific Research (No. 19760617) from the Ministry of Education, Culture, Sports, Science and Technology of Japan (to K. S.).

\section{References}

1. F. Kubota, M. Goto, and F. Nakashio, Solvent Extr. Ion Exch., 1993, 11, 437.

2. K. Ohto, K. Inoue, M. Goto, F. Nakashio, T. Nagasaki, S Shinkai, and T. Kago, Bull. Chem. Soc. Jpn., 1993, 66, 2528.

3. T. Nakamura, S. Nishihama, and K. Yoshizuka, Solvent Extr. Res. Dev., Jpn., 2007, 14, 105.

4. T. Nakamura, K. Ohto, T. Oshima, and K. Inoue, Solvent Extr. Res. Dev., Jpn., 2006, 13, 89.

5. Y. Takebayashi, H. Yajima, and Y. Hasegawa, Solvent Extr. Res. Dev., Jpn., 2007, 14, 121.

6. K. Ohto, M. Yano, K. Inoue, T. Yamamoto, M. Goto, F. Nakashio, S. Shinkai, and T. Nagasaki, Anal. Sci., 1995, 11, 893.

7. H. Naganawa, K. Shimojo, H. Mitamura, Y. Sugo, J. Noro, and M. Goto, Solvent Extr. Res. Dev., Jpn., 2007, 14, 151.

8. H. R. Chang, J. K. McCusker, H. Toftlund, S. R. Wilson, A. 
X. Trautwein, H. Winkler, and D. N. Hendrickson, J. Am. Chem. Soc., 1990, 112, 6814.

9. M. P. Jensen, L. R. Morss, J. V. Beitz, and D. D. Ensor, J. Alloys Compd., 2000, 303 - 304, 137.

10. N. Hirayama, S. Iimuro, K. Kubono, H. Kokusen, and T. Honjo, Anal. Chim. Acta, 1997, 339, 115.

11. K. Takeshita, K. Watanabe, Y. Nakano, and M. Watanabe, Chem. Lett., 2003, 32, 96.

12. Y. Sasaki, Y. Sugo, S. Suzuki, and T. Kimura, Anal. Chim.
Acta, 2005, 543, 31 .

13. K. Ishimori, M. Watanabe, T. Kimura, T. Yaita, T. Yamada, Y. Kataoka, S. Shinoda, and H. Tsukube, Chem. Lett., 2005, $34,1112$.

14. F. Kubota, K. Shinohara, K. Shimojo, T. Oshima, M. Goto, S. Furusaki, and T. Hano, Sep. Purif. Technol., 2001, 24 93.

15. K. Shimojo, H. Naganawa, F. Kubota, and M. Goto, Chem. Lett., 2006, 35, 484. 